\title{
(2) OPEN ACCESS \\ Randomised trial of azithromycin to eradicate Ureaplasma in preterm infants
}

\author{
Rose Marie Viscardi (10, ${ }^{1}$ Michael L Terrin, ${ }^{2}$ Laurence S Magder, ${ }^{2}$ Natalie L Davis, ${ }^{3}$ \\ Susan J Dulkerian, ${ }^{1}$ Ken B Waites, ${ }^{4}$ Namasivayam Ambalavanan, ${ }^{5}$ David A Kaufman, ${ }^{6}$ \\ Pamela Donohue, ${ }^{7}$ Deborah J Tuttle, ${ }^{8}$ Jorn-Hendrik Weitkamp, ${ }^{9}$ Hazem E Hassan, ${ }^{10}$ \\ Natalie D Eddington ${ }^{10}$
}

\begin{abstract}
- Additional material is published online only. To view please visit the journal online (http://dx.doi.org/10.1136/ archdischild-2019-318122).
\end{abstract}

For numbered affiliations see end of article.

Correspondence to Dr Rose Marie Viscardi, Pediatrics, University of Maryland School of Medicine, Baltimore, MD 21201, USA; rviscard@som.umaryland.edu

Received 20 August 2019 Revised 26 January 2020 Accepted 25 February 2020 Published Online First 13 March 2020
Check for updates

(C) Author(s) (or their employer(s)) 2020. Re-use permitted under CC BY-NC. No commercial re-use. See rights and permissions. Published by BMJ.

To cite: Viscardi RM, Terrin ML, Magder LS, et al. Arch Dis Child Fetal Neonatal Ed 2020;105:F615-F622.

\section{ABSTRACT}

Objective To test whether azithromycin eradicates Ureaplasma from the respiratory tract in preterm infants. Design Prospective, phase llb randomised, doubleblind, placebo-controlled trial.

Setting Seven level III-IV US, academic, neonatal intensive care units (NICUs).

Patients Infants $24^{0}-28^{6}$ weeks' gestation (stratified $24^{0}-26^{6} ; 27^{0}-28^{6}$ weeks) randomly assigned within 4 days following birth from July 2013 to August 2016. Interventions Intravenous azithromycin $20 \mathrm{mg} / \mathrm{kg}$ or an equal volume of D5W (placebo) every 24 hours for 3 days.

Main outcome measures The primary efficacy outcome was Ureaplasma-free survival. Secondary outcomes were all-cause mortality, Ureaplasma clearance, physiological bronchopulmonary dysplasia (BPD) at 36 weeks' postmenstrual age, comorbidities of prematurity and duration of respiratory support.

Results One hundred and twenty-one randomised participants (azithromycin: $n=60$; placebo: $n=61$ ) were included in the intent-to-treat analysis (mean gestational age $26.2 \pm 1.4$ weeks). Forty-four of 121 participants (36\%) were Ureaplasma positive (azithromycin: $n=19 ;$ placebo: $n=25)$. Ureaplasma-free survival was 55/60 (92\% (95\% Cl 82\% to 97\%)) for azithromycin compared with $37 / 61$ (61\% (95\% Cl 48\% to $73 \%)$ ) for placebo. Mortality was similar comparing the two treatment groups (5/60 (8\%) vs 6/61 (10\%)). Azithromycin effectively eradicated Ureaplasma in all azithromycin-assigned colonised infants, but 21/25 (84\%) Ureaplasma-colonised participants receiving placebo were culture positive at one or more follow-up timepoints. Most of the neonatal mortality and morbidity was concentrated in 21 infants with lower respiratory tract Ureaplasma colonisation. In a subgroup analysis, physiological BPD-free survival was 5/10 (50\%) (95\% Cl $19 \%$ to $81 \%$ ) among azithromycin-assigned infants with lower respiratory tract Ureaplasma colonisation versus $2 / 11(18 \%)(95 \% \mathrm{Cl} 2 \%$ to $52 \%)$ in placebo-treated infants.

Conclusion A 3-day azithromycin regimen effectively eradicated respiratory tract Ureaplasma colonisation in this study.

Trial registration number NCT01778634.

\section{INTRODUCTION}

Ureaplasma respiratory tract colonisation is an independent risk factor for developing

\section{What is already known on this topic?}

- Respiratory tract colonisation with the genital mycoplasmas Ureaplasma parvum and $U$. urealyticum is an independent risk factor for bronchopulmonary dysplasia in extremely low gestational age infants.

- The azalide antibiotic azithromycin has antiinflammatory properties and exhibits high potency against Ureaplasma isolates in vitro.

- Open-label pharmacokinetic/pharmacodynamics studies of single and multiple dose aizithromycin indicate that $20 \mathrm{mg} / \mathrm{kg} \times 3$ days was most effective in eradicating respiratory tract Ureaplasma in preterms.

\section{What this study adds?}

- In this randomised clinical trial that included 121 infants <29 weeks' gestation, Ureaplasmafree survival was significantly higher in the azithromycin compared with the placebo group.

- Ureaplasma was eradicated in all colonised infants assigned to azithromycin compared with $16 \%$ in colonised infants assigned to placebo.

- Since neonatal mortality and morbidity was concentrated in infants with lower respiratory tract Ureasplasma colonisation, this population should be targeted in future phase III randomised controlled trial.

bronchopulmonary dysplasia (BPD) in preterm infants. ${ }^{1-4}$ Evidence from clinical studies, ${ }^{15}$ and experimental infection models, ${ }^{6-10}$ established lung Ureaplasma as proinflammatory and profibrotic, contributing to BPD alone or when combined with inflammatory stimuli such as hyperoxia or mechanical ventilation. ${ }^{8}$ Whether eradicating Ureasplasma from the developing lung will reduce the risk for BPD is unknown.

Since azithromycin exhibits high potency against clinical Ureaplasma isolates in vitro ${ }^{11}$ and immunomodulatory properties, ${ }^{12}$ it is an appropriate therapeutic candidate to eradicate Ureaplasma and reduce inflammation-mediated BPD in preterm infants. ${ }^{13}$ We conducted open-label, pilot studies characterising the population pharmacokinetics, safety and microbiological efficacy of intravenous 
10 and $20 \mathrm{mg} / \mathrm{kg}$ single dose and $20 \mathrm{mg} / \mathrm{kg}$ x3 d multidose azithromycin in 24-28 week gestation infants. ${ }^{14-16}$ In the open-label, uncontrolled $20 \mathrm{mg} / \mathrm{kg}$ multidose study, azithromycin eradicated Ureaplasma and appeared safe, with no deaths or serious adverse events attributed to the drug. We performed the current pilot (phase IIb) randomised clinical trial to test: (1) the feasibility of recruitment and Ureaplasma detection; (2) whether the 3-day azithromycin regimen was safe and was more effective than placebo to eradicate Ureaplasma in colonised infants; and (3) whether azithromycin would be beneficial or harmful in the subgroups of Ureaplasma-positive and Ureaplasma-negative infants. Respiratory outcomes were explored as potential endpoints for a later phase III trial.

\section{METHODS}

\section{Study design and oversight}

Study design was a prospective, randomised, double-blind, placebo-controlled trial (clinicaltrials.gov NCT01778634). The U.S. Food and Drug Administration (IND78990) and the Institutional Review Board of each participating institution approved the study protocol. Written parental consent was obtained for all participants prior to randomisation. Recruitment was conducted in seven US academic, level III/IV neonatal intensive care units from July 2013 to August 2016. An independent data and safety monitoring committee reviewed unblinded data every 6 months to assess safety and study performance.

\section{Participants}

Eligible participants were extremely low gestation newborns (ELGAN) $24^{0}-28^{6}$ weeks' gestation (November 2013-January 2016), <72-hour postnatal age who received positive pressure ventilation for at least 1 hour. Since rapid diagnostic testing for Ureaplasma was not feasible, presence of Ureaplasma colonisation was not an inclusion criterion and was unknown at the time of recruitment. To focus enrollment on infants with the highest Ureaplasma prevalence, the protocol was revised to limit eligibility to the lower gestation stratum $\left(24^{0}-26^{6}\right.$ weeks) for the last 6 months of enrollment (February-August 2016). Exclusion criteria were: non-viability or planned life support withdrawal; lethal congenital anomalies; >twin gestation; delivery for maternal indications; ECG corrected QT interval $\geq 450 \mathrm{~ms}$; significant hepatic impairment; other systemic macrolide exposure; clinically suspected Ureaplasma CNS infection or cultureconfirmed sepsis; or participation in other clinical trials.

\section{Randomisation and intervention}

Participants were stratified by gestational age $\left(24^{0}-26^{6}\right.$ vs $27^{0}-28^{6}$ weeks) and assigned in 1:1 ratio to azithromycin or placebo using separate randomisation schedules for each clinical site and stratum with twins assigned to the same treatment. The web-based randomisation system (Axio Research, Seattle, Washington, USA) used a permuted block design with varying block sizes of 2, 4 and 6. Baseline respiratory specimens were obtained; infants were randomised; and the first study drug dose administered within 24 hours of signed consent. Participants received azithromycin (American Pharmaceuticals Partners, Schaumburg, Illinois, USA) $20 \mathrm{mg} / \mathrm{kg}$ at a concentration of $2 \mathrm{mg} / \mathrm{mL}$ in $5 \%$ dextrose water or equal volume of $5 \%$ dextrose water $(10 \mathrm{~mL} / \mathrm{kg})$ as a placebo intravenously via a peripheral or central line over $60 \mathrm{~min}$ every 24 hours for three doses. The primary care team at each site determined the fluid management of enrolled patients. Participants, care providers and study staff were blinded to treatment assignment.
Ureaplasma culture, antibiotic susceptibility testing and realtime PCR

Two tracheal aspirates (TAs) at least 2 hours apart and one nasopharyngeal sample from intubated infants, or two nasopharyngeal samples at least 2 hours apart from non-intubated infants were obtained for Ureaplasma culture and PCR before the first dose. Subsequent samples were obtained at 2 and 4-5 days after the last dose and 21 days postnatal age. Each specimen was frozen for later shipment to the University of Alabama at Birmingham Diagnostic Mycoplasma Laboratory for culture and azithromycin susceptibility testing. Species-specific realtime PCR $^{15}$ was performed on all respiratory samples and each Ureaplasma isolate. Culture positivity was defined as a positive 10B broth culture from either TA or nasopharyngeal specimens confirmed by typical morphology. A culture was considered negative after no growth was detected for 7 days. Patients who were culture or PCR positive at any time point were classified as positive. Ureaplasma eradication was defined as three negative cultures post-treatment.

\section{Outcomes}

To accomplish an analysis according to the principle of intention to treat and avoid treating death as a good or neutral outcome, we defined our primary outcome as Ureaplasma-free survival (ie, survival to NICU discharge with three negative cultures posttreatment). Secondary outcomes were mortality, Ureaplasma clearance, physiological BPD at 36 weeks' postmenstrual age (PMA) determined by a room air challenge (RAC), comorbidities of prematurity and duration of respiratory support. Participants were assessed at $36 \pm 1$ weeks' PMA and physiological BPD classified as present if they were receiving positive pressure respiratory support, nasal cannula flow $\geq 4$ liters per minute (LPM or effective fractional inspired oxygen $>0.3^{17-19}$ or failed a RAC. ${ }^{20}$ To compare with BPD rates in other neonatal trials, participants were also classified according to the BPD severity ${ }^{21}$ and the modified Shennan classification ${ }^{22}$ that assigned infants on supplemental oxygen at $36^{\circ}$ week as BPD present regardless of respiratory support and infants discharged home on room air $<36$ weeks' PMA as BPD absent.

\section{Sample size and statistical analysis}

Using a two-sided $\alpha$ level of 0.05 and assuming an $80 \%$ overall survival rate in both groups, $20 \%$ twins and a $25 \%$ placebo clearance rate, ${ }^{23}$ the study would have power of 0.8 to detect an absolute $40 \%$ difference in the primary outcome of Ureaplasmafree survival with enrolment of 30 Ureaplasma-positive infants in each group. With an expected $45 \%$ respiratory prevalence $e^{23}$ and 5\% drop-out rate, we planned to enrol 140 participants. The principal investigator (RV) ended recruitment without any information on the unblinded treatment comparisons when 121 neonates had been randomised because of interruption to funding.

For the efficacy analysis, we compared Ureaplasma eradication and other outcomes among all randomised participants according to the principle of intention to treat and in the subgroups of Ureaplasma-positive and Ureaplasma-negative participants to estimate the extent to which azithromycin had efficacy beyond clearance. To account for possible correlation between outcomes in twins, we used generalised estimating equations ${ }^{24}$ and multiple outputation. ${ }^{25}$ When observed counts were small, we used exact methods without accounting for twinning to calculate $\mathrm{p}$ values and CIs. Additional details of 
Table 1 Baseline characteristics of the study participants for the total cohort and stratified by Ureaplasma status

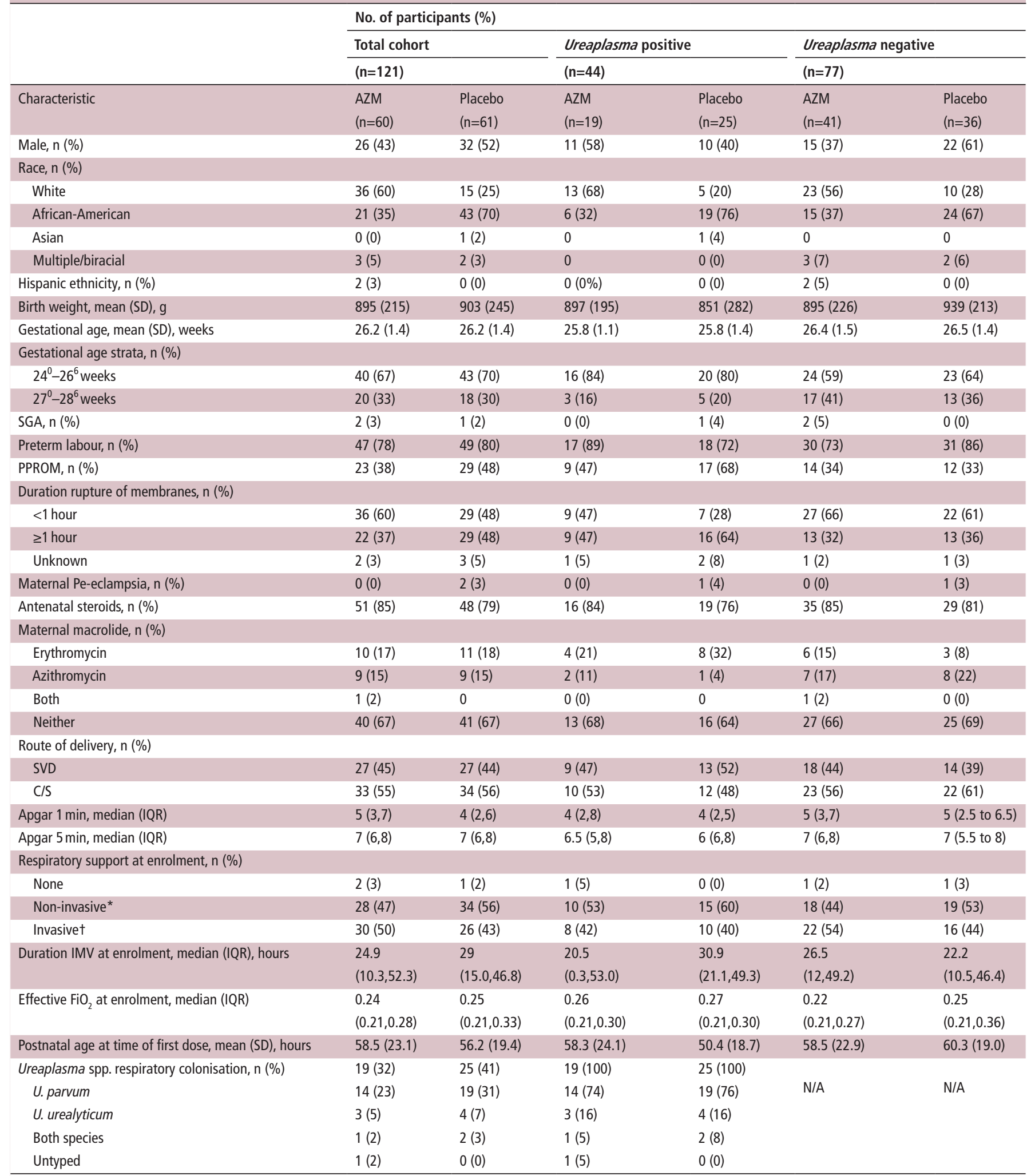

${ }^{*}$ Non-invasive ventilation included oxyhood, low flow nasal cannula, high flow nasal cannula, nasal continuous positive pressure and nasal intermittent positive pressure ventilation.

tInvasive ventilation included synchronised intermittent mechanical ventilation, high frequency oscillatory ventilation and high frequency jet ventilation.

$\mathrm{AZM}$, azithromycin; $\mathrm{C} / \mathrm{S}$, caesarean section; $\mathrm{FiO}_{2}$, fractional inspired oxygen; IMV, intermittent mandatory ventilation; PPROM, preterm premature rupture of membranes; SGA,

small for gestational age; SVD, spontaneous vaginal delivery. 
Table 2 Primary and secondary outcomes of total cohort and stratified by Ureaplasma respiratory colonisation status

\begin{tabular}{|c|c|c|c|c|c|c|c|c|c|}
\hline \multirow[b]{3}{*}{ Outcome } & \multicolumn{9}{|c|}{ No. of participants (\%) } \\
\hline & \multicolumn{3}{|l|}{$\begin{array}{l}\text { Total cohort } \\
(n=121)\end{array}$} & \multicolumn{3}{|c|}{$\begin{array}{l}\text { Ureaplasma positive } \\
(\mathrm{n}=44)\end{array}$} & \multicolumn{3}{|c|}{$\begin{array}{l}\text { Ureaplasma negative } \\
(\mathrm{n}=77)\end{array}$} \\
\hline & $\begin{array}{l}\text { AZM } \\
(n=60)\end{array}$ & $\begin{array}{l}\text { Placebo } \\
(n=61)\end{array}$ & P value* & AZM $(n=19)$ & Placebo $(n=25)$ & P value* & $\begin{array}{l}\text { AZM } \\
(n=41)\end{array}$ & Placebo $(n=36)$ & $\begin{array}{l}P \\
\text { value }^{*}\end{array}$ \\
\hline $\begin{array}{l}\text { Ureaplasma-free } \\
\text { survival, } \mathrm{n}(\%)\end{array}$ & $55(92)$ & $37(61)$ & $<0.001$ & $16(84)$ & $3(12)$ & $<0.001$ & 39 (95) & $34(94)$ & $>0.99$ \\
\hline $\begin{array}{l}\text { Discharged to home, } \\
\mathrm{n}(\%)\end{array}$ & $39(65)$ & $30(49)$ & 0.10 & $13(68)$ & $8(32)$ & 0.03 & $26(63)$ & $22(61)$ & 0.86 \\
\hline $\begin{array}{l}\text { Survival free of } \\
\text { physiological BPD, } \\
n(\%) \dagger\end{array}$ & $31 / 59(53)$ & $36 / 59(61)$ & 0.42 & $9(47)$ & $13 / 24(54)$ & 0.54 & $22(55)$ & $23(66)$ & 0.33 \\
\hline $\begin{array}{l}\text { Moderate-severe } \\
\text { BPD, n (\%)‡ }\end{array}$ & $31 / 57(54)$ & 23/56 (39) & 0.20 & 9/17 (53) & $10 / 22(45 \%)$ & 0.51 & $22 / 40(55)$ & $13 / 34(38)$ & 0.15 \\
\hline $\begin{array}{l}\text { Postnatal steroids } \\
\text { exposure, } \mathrm{n}(\%)\end{array}$ & $15(25)$ & $14(23)$ & 0.86 & $7(37)$ & $6(24)$ & 0.33 & $8(20)$ & $8(22)$ & 0.74 \\
\hline $\begin{array}{l}\text { Passed hearing } \\
\text { screen, } \mathrm{n}(\%) \S\end{array}$ & $50 / 54(93)$ & $52 / 54(96)$ & 0.68 & $13 / 16(81)$ & 19/21 (90) & 0.63 & $37 / 38(97)$ & $33 / 33(100)$ & $>0.99$ \\
\hline $\begin{array}{l}\text { Duration IMV, median } \\
\text { (IQR), days? }\end{array}$ & $12(3-31)$ & $4(1-44)$ & 0.36 & $15(5-66)$ & $3(1-44)$ & 0.25 & $11(2-20)$ & $4(1-47)$ & 0.51 \\
\hline $\begin{array}{l}\text { Duration } \\
\text { supplemental oxygen, } \\
\text { median (IQR), days } ף\end{array}$ & 73 (39-114.5) & $68(33-118)$ & 0.94 & $87(30-140)$ & 75 (55-135) & 0.98 & 70 (40-91) & 60 (26-94) & 0.81 \\
\hline
\end{tabular}

* $P$ values for binary outcomes are based on a score test from generalised estimating equations to account for correlations between twins, or Fisher's exact test when one of the cell sizes has an expectation of less than 5. P values for quantitative outcomes are based on non-parametric tests using multiple outputation to account for correlations between twins.

†Three participants could not be classified with respect to physiological BPD and are excluded from these percentages.

¥Excludes eight participants (three azithromycin and five placebo) who died prior to BPD assessment.

$\S$ Based on only those who survived until discharge but excludes two survivors who did not have a hearing screen.

IIIn computing the median and IQR, those who died are included as having the worst outcomes.

AZM, azithromycin; BPD, bronchopulmonary dysplasia; IMV, intermittent mandatory ventilation.

the statistical analysis plan are described in the online supplementary file 1 .

In post hoc analyses, we explored the impact of lower respiratory tract Ureaplasma colonisation on the primary and major secondary outcomes.

All analyses were performed using SAS V.9.4.

\section{RESULTS}

\section{Study participants}

Infants were recruited from seven sites over 37 months (July 2013-August 2016). A total of 982 patients were screened, of whom $434(44 \%)$ were eligible (online supplementary figure $1 S$ ). Of 121 randomised, 60 were assigned to azithromycin and 61 were assigned to placebo; 119 (98\%) received at least one dose of assigned treatment, one in each treatment group did not receive any doses of assigned treatment and treatment was discontinued in four azithromycin participants (one parent request and three clinical team request). All participants who received $<3$ doses were Ureaplasma negative. One placebo-assigned infant who was nasopharyngeal Ureaplasma positive received a single dose of azithromycin due to pharmacy error.

The baseline characteristics of randomised patients and stratified by Ureaplasma status are summarised in table 1 . An imbalance in race distribution occurred with $40 \%$ non-white in the azithromycin versus $75 \%$ in the placebo group. Other baseline characteristics were similar comparing treatment arms for the entire study cohort and when stratified by Ureaplasma colonisation status.

Forty-four of 121 participants (36\%) were Ureaplasma positive at one or more time points with 19 (32\%) randomised to azithromycin and 25 (41\%) to placebo (table 1 and online supplementary figure $2 \mathrm{~S}$ ). Ureaplasma prevalence was higher in the $24^{0}-26^{6}$ weeks' gestation stratum compared with $27^{0}$ $28^{6}$ weeks $(36 / 83(43 \%)$ vs $8 / 38(21 \%), p=0.02)$. Ureaplasma parvum was the most common species detected in both treatment arms (U. parvum, $\mathrm{n}=33(75 \%) ;$ U. urealyticum $\mathrm{n}=7$ (16\%); both species, $\mathrm{n}=3$ (7\%); untyped $\mathrm{n}=1(2 \%))$. The 
Table 3 Baseline characteristics and outcomes of participants on non-invasive respiratory support, invasive ventilation with TA Ureaplasmanegative specimens and invasive ventilation with TA Ureaplasma-positive specimens

\begin{tabular}{|c|c|c|c|c|}
\hline \multirow[b]{2}{*}{ Outcome } & \multicolumn{3}{|c|}{ No. (\%) of participants* } & \multirow[b]{2}{*}{$P$ value } \\
\hline & $\begin{array}{l}\text { Never intubated } \\
\text { (no TA specimen) } \\
\text { ( } n=47)\end{array}$ & $\begin{array}{l}\text { TA Ureaplasma negative } \\
(\mathrm{n}=52)\end{array}$ & $\begin{array}{l}\text { TA Ureaplasma positive } \\
(\mathrm{n}=21)\end{array}$ & \\
\hline \multicolumn{5}{|l|}{ Baseline characteristics } \\
\hline Male, n (\%) & $24(51)$ & $25(48)$ & $9(43)$ & 0.88 \\
\hline Non-white race, $\mathrm{n}(\%)$ & $34(72)$ & $24(46)$ & $12(57)$ & 0.12 \\
\hline Birth weight, mean (SD), g & 994 (244) & $854(207)$ & 805 (188) & 0.004 \\
\hline Gestational age, mean (SD), weeks & $26.9(1.2)$ & $26.0(1.4)$ & $25.4(1.0)$ & $<0.001$ \\
\hline \multicolumn{5}{|l|}{ Gestational age strata, n (\%) } \\
\hline $24^{0}-26^{6}$ weeks & $24(51)$ & $39(75)$ & $19(90)$ & 0.004 \\
\hline $27^{0}-28^{6}$ weeks & $23(48)$ & $13(25)$ & $2(10)$ & \\
\hline Preterm labour, n (\%) & $37(79)$ & $40(77)$ & $18(86)$ & 0.62 \\
\hline PPROM & $23(49)$ & $16(31)$ & $13(62)$ & 0.03 \\
\hline Antenatal steroids & $39(83)$ & $42(81)$ & $17(81)$ & 0.95 \\
\hline Maternal macrolide exposure & $20(43)$ & $13(25)$ & $6(29)$ & 0.26 \\
\hline C/S delivery & $28(60)$ & $29(56)$ & $9(43)$ & 0.40 \\
\hline Admission WCC $\times 10^{3}$, mean (SD) & $14.5(9.4)$ & $11.3(7.2)$ & $21.4(17.8)$ & 0.05 \\
\hline Ureaplasma spp. respiratory colonisation, n (\%) & $18(38)$ & $5(10)$ & $21(100)$ & 0.01 \\
\hline \multicolumn{5}{|l|}{ Primary and secondary outcomes } \\
\hline Ureaplasma-free survival, n (\%) & $37(78)$ & $46(88)$ & $8(38)$ & 0.002 \\
\hline Survival, $n(\%)$ & $47(100)$ & $47(90)$ & $15(71)$ & $<0.001$ \\
\hline Ureaplasma clearance post-treatment, $\mathrm{n}(\%)$ & $8 / 18(44)$ & $4 / 5(8 \%)$ & $11 / 21(52)$ & 0.44 \\
\hline Survival free of physiological BPD, $n(\%) \ddagger$ & $37 / 45(82)$ & $22 / 51(43)$ & $7(33)$ & $<0.001$ \\
\hline Physiological BPD, $n(\%) \neq \S$ & $8 / 45(18)$ & $26 / 48(54)$ & 9/16 (56) & 0.001 \\
\hline Modified Shennan BPD, $\mathrm{n}(\%) \S$ & $14(29)$ & $28 / 49(57)$ & 9/16 (56) & 0.02 \\
\hline Moderate-severe BPD, $\mathrm{n}(\%) \S$ & $14(29)$ & $30 / 49(61)$ & $9 / 16(56)$ & 0.009 \\
\hline Discharge home, $\mathrm{n}(\%)$ & $33(70)$ & $28(54)$ & $7(33)$ & 0.02 \\
\hline Postnatal steroids exposure, $\mathrm{n}(\%)$ & $3(6)$ & $16(31)$ & $10(48)$ & 0.001 \\
\hline Passed hearing screen, $n(\%) \emptyset$ & $44 / 46$ (96) & $45 / 46(98)$ & $12 / 15(80)$ & 0.27 \\
\hline Total duration IMV, median (IQR) ף * * & $1(1-2)$ & $19.5(9.5-55)$ & $44(24$ to -$)$ & $<0.001$ \\
\hline Total duration supplemental oxygen, median (IQR) $\ddagger^{\star * *}$ & $38(15-64)$ & $85(59-125)$ & 135 (77 to -$)$ & $<0.001$ \\
\hline Duration hospitalisation, median (IQR) $\bigcap^{* *}$ & $71(56-87)$ & $99(81-142)$ & 110 (76 to -$)$ & $<0.001$ \\
\hline
\end{tabular}

${ }^{*}$ One surviving participant with moderate-severe BPD who was discharged home was intubated but had no TA specimens and is not included in this analysis.

tP values for binary outcomes are based on a score test from generalised estimating equations to account for correlations between twins, or Fisher's exact test when one of the cell sizes has an expectation of less than 5. P values for quantitative outcomes are based on non-parametric tests using multiple outputation to account for correlations between twins.

\#Excludes three participants who could not be classified with respect to physiological BPD.

$\S$ Excludes eight participants who died prior to BPD assessment.

१Based on only those who survived until discharge but excludes two survivors who did not have a hearing screen.

${ }^{* *}$ In computing the median and IQR, those who died are included as having the worst outcomes. For the TA Ureaplasma-positive participants, more than $25 \%$ died, so it was not possible to specify the actual 75 th percentile.

$\mathrm{BPD}$, bronchopulmonary dysplasia; C/S, caesarean section; IMV, intermittent mandatory ventilation; PPROM, preterm premature rupture of membranes; TA, tracheal aspirate;

WCC, white cell count.

Minimum inhibitory concentration (MIC) ${ }_{50}$ and $\mathrm{MIC}_{90}$ for Ureaplasma isolates were $2 \mu \mathrm{g} / \mathrm{mL}$ and $4 \mu \mathrm{g} / \mathrm{mL}$, respectively. No tested isolate was resistant to azithromycin (MIC $\geq 16 \mu \mathrm{g} /$ $\mathrm{mL})$.

\section{Efficacy analysis}

The Ureaplasma-free survival was higher in the azithromycin group (92\% (95\% CI 82\% to 97\%)) compared with the placebo group $(61 \%(95 \%$ CI $48 \%$ to $73 \%))(\mathrm{p}<0.001)$ (table 2$)$ and was sustained in analyses stratified by race (online supplementary table 1). For Ureaplasma-positive infants, Ureaplasma-free survival was higher in the azithromycin group (16/19 (84\%), $(95 \%$ CI $60 \%$ to $97 \%))$ than in the placebo group $(3 / 25(12 \%)$, $(95 \%$ CI $3 \%$ to $31 \%))(\mathrm{p}<0.001)$ (table 2$)$. The proportion of infants who survived until discharge was similar in each treatment group (92\% vs $90 \%$, table 2 ). All follow-up cultures were negative in the azithromycin group, but 21/25 (84\%) of colonised placebo subjects were culture positive at one or more follow-up time point (online supplementary figure S2). Seven azithromycin-assigned participants were PCR positive, but culture-negative post-treatment.

\section{Secondary outcomes}

Two-thirds (12/19) of participants who met criteria for RAC, failed and were classified as physiological BPD. Three infants did not have a RAC completed so they could not be classified. There were no significant differences between treatment groups for the entire cohort or stratified by Ureaplasma colonisation status (table 2) or race (online supplementary table 1S) 
Table 4 Primary and secondary outcomes among tracheal aspirate Ureaplasma-positive participants by treatment assignment

\begin{tabular}{|c|c|c|c|}
\hline \multirow[b]{2}{*}{ Outcome } & \multicolumn{2}{|c|}{ No. of participants (\%) } & \multirow[b]{2}{*}{ P value* } \\
\hline & $\begin{array}{l}\text { Azithromycin } \\
(n=10)\end{array}$ & $\begin{array}{l}\text { Placebo } \\
(n=11)\end{array}$ & \\
\hline Ureaplasma-free survival, n (\%) & $8(80)$ & $0(0)$ & $<0.001$ \\
\hline Survival, n (\%) & $8(80)$ & $7(64)$ & 0.64 \\
\hline $\begin{array}{l}\text { Ureaplasma clearance post-treatment, } \\
\mathrm{n}(\%)\end{array}$ & $10(100)$ & $1(9)$ & $<0.001$ \\
\hline $\begin{array}{l}\text { Survival free of physiological BPD, } \\
\mathrm{n}(\%) \dagger\end{array}$ & $5(50)$ & $2(18)$ & 0.18 \\
\hline Physiological BPD, n (\%)† & $3 / 8(38)$ & $6 / 8(75)$ & 0.31 \\
\hline Modified Shennan BPD, n (\%)† & $3 / 8(38)$ & $6 / 8(75)$ & 0.31 \\
\hline Moderate/severe BPD, n (\%)† & $3 / 8(38)$ & $6 / 8(75)$ & 0.31 \\
\hline Discharge home, $\mathrm{n}(\%)$ & $5(50)$ & $2(18)$ & 0.18 \\
\hline Postnatal steroids, n (\%) & $4(40)$ & $6(55)$ & 0.67 \\
\hline Passed hearing screen, $\mathrm{n}(\%) \ddagger$ & $6 / 8(75)$ & 6/7 (86) & $>0.99$ \\
\hline Total duration IMV, median (IQR)§ & $24.5(8-72)$ & $53(31$ to -$)$ & 0.11 \\
\hline $\begin{array}{l}\text { Total duration supplemental oxygen, } \\
\text { median (IQR)§ }\end{array}$ & $95.5(39-174)$ & $\begin{array}{l}142(114 \\
\text { to }-)\end{array}$ & 0.13 \\
\hline $\begin{array}{l}\text { Duration of hospitalisation, median } \\
(\text { IQR)§ }\end{array}$ & $80.5(27-173)$ & 134 (91 to -$)$ & 0.08 \\
\hline
\end{tabular}

${ }^{*} \mathrm{P}$ values for categorical outcomes are based on Fisher's exact tests. $P$ values for quantitative analysis are based on two-sample Wilcoxon tests.

tExcludes five participants (two azithromycin, three placebo) who died prior to 36 weeks PMA.

¥Excludes six (two azithromycin, four placebo) participants who died before hearing screen was obtained.

§In computing the median and IQR, those who died are included as having the worst outcomes. For the tracheal aspirate Ureaplasma-positive participants, more than $25 \%$ died, so it was not possible to specify the actual 75 th percentile.

BPD, bronchopulmonary dysplasia; IMV, intermittent mandatory ventilation; PMA, postmenstrual age.

in overall survival, physiological BPD-free survival, frequency BPD by any classification or other secondary outcomes.

\section{Post hoc analyses}

Patients with lower respiratory tract Ureaplasma colonisation $(n=21)$ were of lower gestation and birth weight than TA-negative intubated participants $(n=52)$ and non-intubated infants $(n=47)$ (table 3). In 5/52 (10\%) TA-negative and 18/47 (38\%) non-intubated neonates, one or more nasopharyngeal samples were Ureaplasma positive. Outcomes including Ureaplasma-free survival, overall survival, physiological BPD-free survival, durations of hospitalisation, mechanical ventilation and supplemental oxygen and postnatal steroid exposure were less favourable in patients with lower respiratory tract Ureaplasma colonisation than intubated infants without lower tract involvement or nonintubated patients (table 3). In patients with lower respiratory tract Ureaplasma colonisation, physiological BPD-free survival was $50 \%(5 / 10),(95 \%$ CI $19 \%$ to $81 \%)$ in azithromycin-treated versus $18 \%(2 / 11),(95 \%$ CI $2 \%$ to $52 \%)$ in placebo-treated infants $(\mathrm{p}=0.18)$ (table 4$)$.

\section{Safety}

Common morbidities of prematurity occurring after randomisation and prior to hospital discharge were similar between treatment groups (table 5) and when stratified by race (online supplementary table 2S). Posthaemorrhagic hydrocephalus $(\mathrm{PHH})$ was more common in the azithromycin-assigned compared with the placebo group (6 vs 0 ). Prior to dosing, IVH status was unknown in $4 / 6$ of these infants; $1 / 6$ had grade 2
IVH; and 1/6 received no azithromycin. Among those assigned to azithromycin, $11 / 56(20 \%)$ had retinopathy of prematurity (ROP) > stage 2 compared with 4/56 (7\%) assigned to placebo. ROP was more common in white infants in both treatment groups than non-white infants, which appears to explain most of this difference (online supplementary table $2 \mathrm{~S}$ ). There were no reported cases of infantile hypertrophic pyloric stenosis (IHPS) or QT-interval prolongation.

\section{DISCUSSION}

This pilot clinical trial demonstrates that: (1) respiratory tract Ureaplasma colonisation persists in untreated infants during the first three postnatal weeks; (2) $20 \mathrm{mg} / \mathrm{kg} \mathrm{x3d}$ intravenous azithromycin effectively eradicates Ureaplasma from the respiratory tract in colonised ELGAN infants; and (3) ELGANs with lower respiratory tract Ureaplasma colonisation are a high risk group to target in future randomised trials. There is no evidence of an impact of azithromycin among Ureaplasma-negative infants.

The Ureasplasma eradication rate $(100 \%)$ with the 3 days $20 \mathrm{mg} / \mathrm{kg} /$ day azithromycin regimen that was based on our open-label pharmacokinetics/pharmacodynamics studies ${ }^{14-16}$

Table 5 Morbidities of prematurity by treatment group

\begin{tabular}{|c|c|c|c|}
\hline & $\begin{array}{l}\text { Azithromycin } \\
(n=60)\end{array}$ & Placebo $(n=61)$ & \\
\hline Morbidity & $\begin{array}{l}\mathrm{N}(\%) \text { acquired } \\
\text { prior to discharge }\end{array}$ & $\begin{array}{l}\mathrm{N}(\%) \text { acquired } \\
\text { prior to discharge }\end{array}$ & $P$ value* \\
\hline Pneumothorax & $7 / 55(13)$ & $4 / 57(7)$ & 0.49 \\
\hline PDA & $25 / 55(45)$ & $21 / 56(38)$ & 0.33 \\
\hline Feeding intolerance & 20/51 (39) & $34 / 58(59)$ & 0.04 \\
\hline Gastro-oesophageal reflux & $14 / 60(23)$ & 11/61 (18) & 0.54 \\
\hline Intestinal perforation & $2 / 60(3)$ & $4 / 61(7)$ & 0.68 \\
\hline NEC $\geq$ stage 2 & $4 / 60(7)$ & $5 / 61(8)$ & $>0.99$ \\
\hline Culture-confirmed sepsis & $8 / 60(13)$ & 14/61 (23) & 0.18 \\
\hline IVHt & & & 0.33 \\
\hline None & $31 / 53(58)$ & $40 / 54(74)$ & \\
\hline Grade 1 & 10/53 (19) & $7 / 54(13)$ & \\
\hline Grade 2 & $5 / 53(9)$ & $5 / 54(9)$ & \\
\hline Grade 3 & $5 / 53(9)$ & $1 / 54(2)$ & \\
\hline Grade 4 & $2 / 53(4)$ & $1 / 54(2)$ & \\
\hline Shunted PHH & $6 / 60(10) \ddagger$ & $0 / 61(0)$ & 0.01 \\
\hline PVL & $4 / 60(7)$ & $5 / 61(8)$ & $>0.99$ \\
\hline ROP (highest stage)§ & & & 0.28 \\
\hline None & $18 / 56(32)$ & $25 / 56(45)$ & \\
\hline Stage 1 & $17 / 56(30)$ & $17 / 56(30)$ & \\
\hline Stage 2 & $10 / 56(18)$ & $10 / 56(18)$ & \\
\hline Stage 3 & $11 / 56(20)$ & $3 / 56(5)$ & \\
\hline Stage 4 & $0 / 56(0)$ & $1 / 56(2)$ & \\
\hline
\end{tabular}

* $P$ values for binary outcomes are based on a score test from generalised estimating equations to account for correlations between twins, or Fisher's exact test when one of the cell sizes has an expectation of less than 5.

tThe IVH proportions exclude 12 participants who had IVH prior to their first dose and who did not progress. It also excludes two who never received the treatment to which they were randomised.

¥For azithromycin-assigned participants with shunted PHH, IVH status at baseline was unknown in four participants; grade 2 in one participant; and one infant was never dosed.

$\S$ Four assigned to azithromycin and five assigned to placebo were never assessed for ROP and are not included.

IVH, intraventricular haemorrhage; NEC, necrotising enterocolitis; PDA, patent ductus arteriosus; $\mathrm{PHH}$, posthaemorrhagic hydrocephalus; PVL, periventricular leukomalacia; ROP, retinopathy of prematurity. 
was higher than but not inconsistent with eradication rates in previous trials of erythromycin $(82 \%-86 \%)^{26} 27$ and clarithromycin $(68.5 \%){ }^{28}$ However, some infants in the azithromycin group remained PCR-positive after treatment. This may represent residual DNA from dead organisms since no isolate was resistant. Effective clearance likely is dependent on factors such as pathogen virulence ${ }^{1}$ and variability in host immune response due to polymorphisms in host defence genes that may alter susceptibility to Ureaplasma and the inflammatory response. ${ }^{29}$

No current BPD definition is a strong predictor of long-term pulmonary outcomes. ${ }^{30}$ The recent increase in use of noninvasive respiratory support with room air has challenged classifications of BPD based on supplemental oxygen use. We selected three common BPD definitions as exploratory outcomes in the current trial. Completion of the study 2-year follow-up will allow us to compare the modified Shennan, ${ }^{22}$ BPD severity and physiological definitions' predictive ability for later respiratory outcomes to better design a definitive phase III clinical trial.

Published reports on racial differences in preterm outcomes differ on which races experience more adverse perinatal outcomes $^{31-33}$ or whether differences exist. ${ }^{34}$ In a recent prospective cohort of infants $<29$ weeks' gestation, Wai et $a l^{35}$ observed a lower incidence of BPD in black than white infants, but the frequency of respiratory morbidity during the first year of life was higher in black than white infants. In the Trial of Late Surfactant for Prevention of BPD (TOLSURF) clinical trial, black infants administered inhaled nitric oxide were less likely to develop BPD but experienced greater frequency of wheezing illness in the first $18-24$ months of life. ${ }^{35} 36$ Since there was an imbalance by race in treatment groups in the current trial, we examined outcomes stratified by race. Our primary outcome finding of greater Ureaplasma-free survival with azithromycin was sustained in analyses stratified for race.

Azithromycin side effects are infrequent in adults and children. ${ }^{37}$ A recent study demonstrated an association of IHPS with oral azithromycin exposure in the first $14 \mathrm{~d}$ of life in term ${ }^{38}$ and preterms 33-36 weeks' gestation but not $\leq 32$ weeks' gestation. ${ }^{39}$ In addition, azithromycin is proarrhythmogenic with prior reports of occurrences of QT-interval prolongation and torsades de pointes in adults. ${ }^{40}$ Although there were no reported incidences of IHPS or QT interval prolongation in the infants in the current trial, adverse events must be monitored closely in any subsequent trial of azithromycin in the ELGAN population.

\section{Study limitations}

Since Ureaplasma spp. lack cell walls, they are susceptible to drying and heat contributing to false negatives, so that some affected infants may have been missed. We made efforts to avoid this misclassification by providing central laboratory culture medium, collection procedures optimised for organism recovery, multiple sampling sites at timepoints before and after study treatment and inclusion of PCR methods to better detect Ureaplasma. The race imbalance in randomisation did not influence the primary outcome, Ureaplasma-free survival, but influenced some secondary clinical outcomes. Future trials should consider stratifying on race. Brain imaging prior to randomisation was not required for this trial but, due to the observed differences in $\mathrm{PHH}$, may be warranted in any future trial to better delineate the timing of IVH in relation to treatment.

\section{Study implications summary}

The results of this trial demonstrate the efficacy of azithromycin to eradicate Ureaplasma in ELGAN infants but do not support treatment of all ELGAN infants with azithromycin. Perinatal mortality and prolonged respiratory support are concentrated in ELGANs who have Ureaplasma in the lower respiratory tract. A phase III clinical trial in ELGAN infants with lower respiratory tract Ureaplasma would determine whether or not a 3-day course of azithromycin is of clinical benefit.

\section{Author affiliations}

'Department of Pediatrics, University of Maryland School of Medicine, Baltimore, Maryland, USA

${ }^{2}$ Department of Epidemiology and Preventive Medicine, University of Maryland School of Medicine, Baltimore, Maryland, USA

${ }^{3}$ Department of Pediatrics, University of Maryland Baltimore, Baltimore, Maryland, USA

${ }^{4}$ Department of Pathology, University of Alabama at Birmingham, Birmingham, Alabama, USA

${ }^{5}$ Department of Pediatrics, University of Alabama at Birmingham, Birmingham, Alabama, USA

${ }^{6}$ Department of Pediatrics, University of Virginia School of Medicine, Charlottesville, Virginia, USA

${ }^{7}$ Department of Pediatrics, Johns Hopkins Medicine, Baltimore, Maryland, USA ${ }^{8}$ Department of Pediatrics, Christiana Care Health System, Newark, Delaware, USA ${ }^{9}$ Department of Pediatrics, Vanderbilt University Medical Center, Nashville, Tennessee, USA

${ }^{10}$ University of Maryland School of Pharmacy, Baltimore, Maryland, USA

Correction notice This paper has been updated since it was published online. Author Namasivayam Ambalavanan's first and last name were reversed and this has now been corrected.

Acknowledgements We would like to thank the parents of the participants of this trial and staff of participating NICUs and site study coordinators Elise Janofsky, Ashley Bathgate, Jennifer Shepard, Monika J. Thielen, Tara McNair, Amy Mackley, Kelly Gray and Steven Steele for assistance with patient recruitment. No compensation was received other than salary support for their contribution. We would like to thank the University of Alabama Diagnostic Mycoplasma Laboratory staff Donna Crabb and Melanie Fecanan for Ureaplasma culture and susceptibility testing and Amy Ratliffe for PCR. We would like to thank the University of Maryland School of Medicine Clinical and Translational Research Informatics Center for data management.

Contributors RV, MLT, LSM and NLD had full access to all of the data in the study and take responsibility for the integrity of the data and accuracy of the data analysis. Study concept and design: RV, MLT, LSM and NDE. Acquisition, analysis or data interpretation: all authors. Drafting of the manuscript: RV, MLT and LSM. Critical revision of the manuscript: all authors. Statistical Analysis: RV, MLT, LSM and NLD. Obtained funding: RV, MLT, LSM, SJD, PD, DAK, KBW, AN and NDE. Study supervision: RV, MLT, SJD, PD, DAK, AN, DJT, J-HW and KBW.

Funding This study was funded by Eunice Kennedy Shriver National Institute of Child Health and Human Development (NICHD) (R01 HD067126). NICHD had no role in the design and conduct of the study; data collection, management, analysis, and interpretation; preparation, review, or approval prior to submission of the manuscript.

Disclaimer The views expressed in this publication are those of the authors and not necessarily the views of the Eunice Kennedy Shriver National Institute of Child Health and Human Development.

Competing interests None declared.

Patient consent for publication Not required.

Provenance and peer review Not commissioned; externally peer reviewed.

Data availability statement Data are available in a public, open access repository. Deidentified data analysis file, study protocol and statistical analysis plan will be accessible on the NICHD Data and Specimen Hub (URL pending)

Open access This is an open access article distributed in accordance with the Creative Commons Attribution Non Commercial (CC BY-NC 4.0) license, which permits others to distribute, remix, adapt, build upon this work non-commercially, and license their derivative works on different terms, provided the original work is properly cited, appropriate credit is given, any changes made indicated, and the use is non-commercial. See: http://creativecommons.org/licenses/by-nc/4.0/.

ORCID iD

Rose Marie Viscardi http://orcid.org/0000-0001-7451-6059 


\section{REFERENCES}

1 Viscardi RM, Kallapur SG. Role of Ureaplasma respiratory tract colonization in bronchopulmonary dysplasia pathogenesis: current concepts and update. Clin Perinatol 2015;42:719-38.

2 Wang EE, Cassell GH, Sánchez PJ, et al. Ureaplasma urealyticum and chronic lung disease of prematurity: critical appraisal of the literature on causation. Clin Infect Dis 1993;17 Suppl 1:S112-6.

3 Schelonka RL, Katz B, Waites KB, et al. Critical appraisal of the role of Ureaplasma in the development of bronchopulmonary dysplasia with metaanalytic techniques. Pediatr Infect Dis J 2005:24:1033-9.

4 Lowe J, Watkins WJ, Edwards MO, et al. Association between pulmonary Ureaplasma colonization and bronchopulmonary dysplasia in preterm infants: updated systematic review and meta-analysis. Pediatr Infect Dis J 2014;33:697-702.

5 Silwedel C, Speer CP, Glaser K. Ureaplasma-associated prenatal, perinatal, and neonatal morbidities. Expert Rev Clin Immunol 2017;13:1073-87.

6 Normann E, Lacaze-Masmonteil T, Eaton F, et al. A novel mouse model of Ureaplasmainduced perinatal inflammation: effects on lung and brain injury. Pediatr Res 2009;65:430-6.

7 Moss TJM, Knox CL, Kallapur SG, et al. Experimental amniotic fluid infection in sheep: effects of Ureaplasma parvum serovars 3 and 6 on preterm or term fetal sheep. Am J Obstet Gynecol 2008;198:122.e1-122.e8.

8 Viscardi RM, Atamas SP, Luzina IG, et al. Antenatal Ureaplasma urealyticum respiratory tract infection stimulates proinflammatory, profibrotic responses in the preterm baboon lung. Pediatr Res 2006;60:141-6.

9 Grigsby PL, Novy MJ, Sadowsky DW, et al. Maternal azithromycin therapy for Ureaplasma intraamniotic infection delays preterm delivery and reduces fetal lung injury in a primate model. Am J Obstet Gynecol 2012;207:475.e1-475.e14.

10 Glaser K, Silwedel C, Fehrholz M, et al. Ureaplasma species differentially modulate pro- and anti-inflammatory cytokine responses in newborn and adult human monocytes pushing the state toward pro-inflammation. Front Cell Infect Microbiol 2017;7:484

11 Pandelidis K, McCarthy A, Chesko KL, et al. Role of biofilm formation in Ureaplasma antibiotic susceptibility and development of bronchopulmonary dysplasia in preterm neonates. Pediatr Infect Dis J 2013:32:394-8.

12 Parnham MJ, Erakovic Haber V, Giamarellos-Bourboulis EJ, et al. Azithromycin: mechanisms of action and their relevance for clinical applications. Pharmacol Ther 2014;143:225-45.

13 Turner MA, Jacqz-Aigrain E, Kotecha S. Azithromycin, Ureaplasma and chronic lung disease of prematurity: a case study for neonatal drug development. Arch Dis Child 2012;97:573-7.

14 Hassan HE, Othman AA, Eddington ND, et al. Pharmacokinetics, safety, and biologic effects of azithromycin in extremely preterm infants at risk for Ureaplasma colonization and bronchopulmonary dysplasia. J Clin Pharmacol 2011;51:1264-75.

15 Viscardi RM, Othman AA, Hassan HE, et al. Azithromycin to prevent bronchopulmonary dysplasia in ureaplasma-infected preterm infants: pharmacokinetics, safety, microbial response, and clinical outcomes with a 20-milligram-per-kilogram single intravenous dose. Antimicrob Agents Chemother 2013;57:2127-33.

16 Merchan LM, Hassan HE, Terrin ML, et al. Pharmacokinetics, microbial response, and pulmonary outcomes of multidose intravenous azithromycin in preterm infants at risk for Ureaplasma respiratory colonization. Antimicrob Agents Chemother 2015:59:570-8.

17 Benaron DA, Benitz WE. Maximizing the stability of oxygen delivered via nasal cannula. Arch Pediatr Adolesc Med 1994:148:294-300.

18 Group SRMS. Supplemental therapeutic oxygen for prethreshold retinopathy of prematurity (STOP-ROP), a randomized, controlled trial. I: primary outcomes. Pediatrics 2000; 105:295-310.
19 Walsh MC, Yao Q, Gettner P, et al. Impact of a physiologic definition on bronchopulmonary dysplasia rates. Pediatrics 2004;114:1305-11.

20 Natarajan G, Pappas A, Shankaran S, et al. Outcomes of extremely low birth weight infants with bronchopulmonary dysplasia: impact of the physiologic definition. Early Hum Dev 2012;88:509-15.

21 Jobe AH. The new bronchopulmonary dysplasia. Curr Opin Pediatr 2011;23:167-72.

22 Poindexter BB, Feng R, Schmidt B, et al. Comparisons and limitations of current definitions of bronchopulmonary dysplasia for the prematurity and respiratory outcomes program. Ann Am Thorac Soc 2015;12:1822-30.

23 Sung T-J, Xiao L, Duffy L, et al. Frequency of Ureaplasma serovars in respiratory secretions of preterm infants at risk for bronchopulmonary dysplasia. Pediatr Infect Dis J 2011;30:379-83.

24 Zeger SL, Liang KY, Albert PS. Models for longitudinal data: a generalized estimating equation approach. Biometrics 1988;44:1049-60.

25 Follmann D, Proschan M, Leifer E. Multiple outputation: inference for complex clustered data by averaging analyses from independent data. Biometrics 2003:59:420-9.

26 Jónsson B, Rylander M, Faxelius G. Ureaplasma urealyticum, erythromycin and respiratory morbidity in high-risk preterm neonates. Acta Paediatr 1998;87:1079-84

27 Baier RJ, Loggins J, Kruger TE. Failure of erythromycin to eliminate airway colonization with Ureaplasma urealyticum in very low birth weight infants. BMC Pediatr 2003;3:10.

28 Ozdemir R, Erdeve O, Dizdar EA, et al. Clarithromycin in preventing bronchopulmonary dysplasia in Ureaplasma urealyticum-positive preterm infants. Pediatrics 2011;128:e1496-501.

29 Winters AH, LeVan TD, Vogel SN, et al. Single nucleotide polymorphism in Toll-like receptor 6 is associated with a decreased risk for Ureaplasma respiratory tract colonization and bronchopulmonary dysplasia in preterm infants. Pediatr Infect Dis 2013:32:1-904.

30 Steinhorn R, Davis JM, Göpel W, et al. Chronic pulmonary insufficiency of prematurity: developing optimal endpoints for drug development. J Pediatr 2017;191:15-21.

31 Wallace ME, Mendola P, Kim SS, et al. Racial/Ethnic differences in preterm perinatal outcomes. Am J Obstet Gynecol 2017;216:306.e1-306.e12

32 Laughon MM, Langer JC, Bose CL, et al. Prediction of bronchopulmonary dysplasia by postnatal age in extremely premature infants. Am J Respir Crit Care Med 2011;183:1715-22.

33 Ying G-S, Quinn GE, Wade KC, et al. Predictors for the development of referralwarranted retinopathy of prematurity in the telemedicine approaches to evaluating acute-phase retinopathy of prematurity (e-ROP) study. JAMA Ophthalmol 2015;133:304-11.

34 Petrova A, Mehta R, Anwar M, et al. Impact of race and ethnicity on the outcome of preterm infants below 32 weeks gestation. J Perinatol 2003;23:404-8.

35 Wai KC, Hibbs AM, Steurer MA, et al. Maternal black race and persistent wheezing illness in former extremely low gestational age newborns: secondary analysis of a randomized trial. J Pediatr 2018;198:201-8.

36 Ballard RA, Keller RL, Black DM, et al. Randomized trial of late surfactant treatment in ventilated preterm infants receiving inhaled nitric oxide. J Pediatr 2016;168:23-9.

37 Ruuskanen 0. Safety and tolerability of azithromycin in pediatric infectious diseases: 2003 update. Pediatr Infect Dis J 2004;23:S135-9.

38 Eberly MD, Eide MB, Thompson JL, et al. Azithromycin in early infancy and pyloric stenosis. Pediatrics 2015;135:483-8.

39 Stark CM, Rogers PL, Eberly MD, et al. Association of prematurity with the development of infantile hypertrophic pyloric stenosis. Pediatr Res 2015;78:218-22.

40 Ray WA, Murray KT, Hall K, et al. Azithromycin and the risk of cardiovascular death. $N$ Engl J Med 2012;366:1881-90. 